\title{
PERFIL DA FALA DO RESPIRADOR ORAL
}

\author{
Speech profile of the mouth breather
}

\author{
Cintia Megumi Nishimura (1), Sandra Rosa Machado Luz Gimenez (2)
}

\begin{abstract}
RESUMO
Tema: alteração de fala em respiradores orais. Objetivo: o presente estudo investigou através de levantamento bibliográfico dos últimos dez anos o perfil de fala em respiradores orais. Conclusão: constata-se a necessidade em realizar estudos mais profundos sobre este assunto para identificar as características da fala dos respiradores orais. Tais informações são muito úteis para o fonoaudiólogo, tanto para a realização de uma boa avaliação como no melhor atendimento destes indivíduos.
\end{abstract}

DESCRITORES: Respiração Bucal; Distúrbios da Fala; Fala

\section{INTRODUÇÃO}

Com o passar dos anos, aumentou o número de indivíduos que apresentam problemas respiratórios, sendo que em alguns casos, são de difícil diagnóstico e tratamento.

A respiração oral, entre diversos problemas, pode ocasionar alteração da fala. A articulação dos sons depende da mobilidade da língua, lábios e bochechas e, da posição dos dentes, mandíbula e língua ${ }^{1}$, necessitando de posicionamentos e movimentos precisos dos articuladores, que somente são viáveis na presença de uma adequada estrutura morfológica orofacial ${ }^{2}$. Os problemas de fala podem ser causados por alterações de mobilidade, tônus e postura dos órgãos fonoarticulatórios e alterações das estruturas orofaciais, muito comum em respiradores orais.

A partir de novas pesquisas sobre a fala do respirador oral, o fonoaudiólogo terá a oportunidade de compartilhar seus achados clínicos com a literatura, tornando desta forma, seu atendimento mais funcional e preciso. É importante investigar as

(1) Fonoaudióloga; Clínica Cíntia Nishimura, Maringá, PR, Brasil; Aperfeiçoamento em Voz pelo INVOZ - Instituto de Comunicação e Voz Profissional; Especialista em Voz pelo Conselho Federal de Fonoaudiologia; Especialização em Motricidade Orofacial; Mestranda em Educação na Universidade Estadual de Maringá.

(2) Fonoaudióloga; Clínica Sandra Gimenez, Maringá, PR, Brasil; Especialista em Motricidade Orofacial pelo ConseIho Federal de Fonoaudiologia; Mestre em Distúrbios da Comunicação pela Universidade Tuiuti do Paraná.

Conflito de interesses: inexistente alterações de fala em respiradores orais, visto que há escassez de estudos que versem exclusivamente sobre distorções articulatórias nessa população e, os poucos trabalhos existentes, abordam sobre as alterações de fala indiretamente.

Este estudo teve como objetivo verificar na literatura científica, o perfil de fala do respirador oral.

\section{MÉTODOS}

Foi realizado um levantamento bibliográfico durante o ano de 2008, priorizando os estudos nacionais. A pesquisa foi realizada em 21 periódicos dos últimos dez anos, disponíveis no Portal Periódicos da CAPES, sendo cinco da área de fonoaudiologia, um de otorrinolaringologia, seis de odontologia, um de ortodontia, três de pediatria, dois de pneumologia, dois de psicopedagogia, um de reumatologia e dois de fisioterapia, a fim de verificar o perfil de fala em indivíduos com respiração oral. Foi realizado um levantamento bibliográfico também de monografias e dissertações online, de revistas nacionais de fonoaudiologia não encontradas no Portal Periódicos da CAPES e de livros. As palavras chaves utilizadas na pesquisa foram: respiração oral, respiração bucal, distúrbios da fala e fala dos respiradores orais.

\section{REVISÃO DA LITERATURA}

A respiração é uma função vital que interfere no organismo como um todo ${ }^{3}$. As principais funções do nariz são: filtração, aquecimento e umidificação do ar inspirado ${ }^{4}$. A filtração do ar e a proteção das 
vias aéreas inferiores são realizadas pelos pêlos, função ciliar e ação química bactericida do muco. As conchas nasais, uma das partes internas do nariz, regulam o fluxo respiratório com o aumento do seu volume. O aquecimento do ar é garantido pela irrigação de calor e a umidificação é fornecida pelo contato do ar com o líquido seroso existente na cavidade nasal, com a secreção lacrimal e com o muco que adere partículas estranhas por conter um fermento bactericida. Essas funções condicionam o ar que chega aos pulmões ${ }^{5}$.

A respiração nasal favorece o crescimento e desenvolvimento craniofacial, cujo processo fisiológico inicia-se a partir da passagem do ar pelo nariz ${ }^{6}$.

A principal causa da respiração oral são as doenças obstrutivas, tais como: rinite alérgica, hipertrofia das tonsilas palatinas e faríngeas ${ }^{7}$. Essas doenças obrigam o indivíduo a modificar o padrão respiratório nasal para oral. A obstrução nasal é muito comum na infância ${ }^{8}$.

O respirador oral apresenta características inconfundíveis: lábios entreabertos, língua no soaIho bucal, hiperfunção do músculo mentual ao realizar o vedamento labial, lábio inferior com eversão, problemas de oclusão dentária ${ }^{9}$, palato atrésico e ogival ${ }^{10}$, flacidez de bochechas e aumento da altura da face ${ }^{11}$. A fala pode ser imprecisa com presença de sigmatismo anterior ou lateral e a voz pode ser alterada pelo ressecamento dos tecidos da laringe que prejudica a vibração das pregas vocais ${ }^{12}$.

As consequências da respiração oral, muitas vezes são irreversíveis para o crescimento e desenvolvimento da criança como: alterações posturais ${ }^{13,14}$, craniofaciais ${ }^{15,16}$, oclusais ${ }^{17,18}$, auditivas ${ }^{19}$, vocais ${ }^{17}$, articulatórias ${ }^{13,18,19}$, nas funções estomatognáticas ${ }^{13,19}$, dos órgãos fonoarticulatórios ${ }^{14,15}$, redução de apetite, dificuldades de atenção e concentração, agitação, ansiedade ${ }^{14}$ e dificuldade na aprendizagem ${ }^{13,14,20}$, desempenho inferior de habilidades fonológicas ${ }^{7}$ e envelhecimento facial precoce em comparação aos respiradores nasais, destacando-se maior presença de olheiras, rugas abaixo dos olhos, sulco mento-labial, face discretamente alongada na região das bochechas e maior desproporção facial ${ }^{21}$.

Além dos problemas de respiração, mastigação, deglutição, postura e tonicidade dos órgãos fonoar- ticulatórios, os respiradores orais podem apresentar também distúrbio articulatório 22,23.

A má-oclusão, uma das principais características do respirador oral pode acarretar dificuldades ou desvios de produção fonético/articulatório ${ }^{24}$.

Entretanto, existem poucos trabalhos que relatam a ocorrência de distúrbios articulatórios decorrentes a este tipo de respiração.

Foram encontrados estudos relacionados ao respirador oral como: tipos de respirador oral ${ }^{22}$, estudos cefalométricos ${ }^{25}$, alterações craniofaciais ${ }^{26}$, periodontais ${ }^{27}$, faciais ${ }^{22,28}$, comportamentais ${ }^{28}$, posturais ${ }^{14,29}$, dos órgãos fonoarticulatórios $^{30}$, da força de língua ${ }^{31}$, do estado nutricional ${ }^{32}$, dos problemas de aprendizagem em crianças com obstrução das vias aéreas superiores associados às dificuldades de atenção ${ }^{20}$, correlação de problemas posturais com a aprendizagem ${ }^{13}$, associação da respiração oral com o transtorno de déficit de atenção e hiperatividade ${ }^{33}$.

Constatou-se escassez na literatura nacional dos últimos 10 anos sobre a fala dos respiradores orais. Foram encontrados 38 estudos sobre respiração oral, e destes, somente um sobre a fala desses indivíduos.

Devido à diversidade de achados morfo-funcionais, a atuação multidisciplinar é muito importante para o respirador oral ${ }^{7,13}$. Pensando neste aspecto, o respirador oral pode se beneficiar muito com a terapia fonoaudiológica, pois esta permite a reabilitação funcional do sistema estomatognático.

\section{CONCLUSÃO}

Constata-se que há necessidade em realizar estudos específicos sobre a fala em respiradores orais, com o objetivo de averiguar a prevalência e identificar as alterações mais frequentes, visto que, em alguns casos, apenas a terapia miofuncional orofacial possibilita indiretamente e diretamente a melhora da fala, principalmente em crianças. Muitos respiradores orais procuram o tratamento fonoaudiológico para amenizar as consequências causadas por esta alteração, com isso a identificação das características de fala é útil para o fonoaudiólogo, tanto na avaliação como no atendimento destes indivíduos, possibilitando inclusive a elucidação do prognóstico. 


\section{ABSTRACT}

Background: alteration of speech in mouth breathers. Purpose: this study carried out a bibliographic review over the last ten years about mouth breathers' speech profile. Conclusion: there is a need to carry out more thorough studies on this subject to identify the speech characteristics of mouth breathers. Such information is very useful for the speech therapist, both for making a good assessment as well as for providing the best care for these individuals.

KEYWORDS: Mouth Breathing; Speech Disorders; Speech

\section{REFERÊNCIAS}

1. Camargo MEPS. Respiração: movimento de vida. Rev Temas sobre Desenvolv. 2004; 13(77):27-36.

2. Castro FFM. Rinite alérgica: modernas abordagens para uma clássica questão. 2. ed. São Paulo: Lemos; 1998.

3. Camargo MEPS. Respiração: movimento de vida. Rev Temas Desenvolv. 2004; 13(77):27-36.

4. Di Francisco RC. Consequências da respiração oral: quando indicar a cirurgia. In: krakauer LH, Difrancesco RC, Marchesan IQ. Respiração oral: conhecimentos essenciais para entender bem a respiração oral. São José dos Campos: Pulso; 2003. p. 19-25.

5. Hungria E. Cavidade nasal. In: Hungria E. Otorrinolaringologia. 2. ed. Rio de Janeiro: Guanabara Koogan; 2000. p. 443-7.

6. Rodrigues HOSN, Faria SR, Paula FSG, Motta AR. Ocorrência de respiração oral e alterações miofuncionais orofaciais em sujeitos em tratamento ortodôntico. Rev. CEFAC. 2005; 7(3):356-62.

7. Di Francisco RC. Respirador bucal: a visão do otorrinolaringologista. J Bras Fonoaudiol. 1999; 1(1):56-60.

8. Figueiredo CR, Freitas PZ, Pignatari SN. Rinite alérgica. Rev Bras Med. 2004; 61(Supl Esp):91-7.

9. Cattoni DM, Fernandes FDM, Di Francesco RC, Latorre MRDO. Características do sistema estomatognático de crianças respiradoras orais: enfoque antroposcópico. Pró-Fono. 2007; 19(4):347-51.

10. Motonaga SM, Berte LC, Anselmo-Lima WT. Respiração bucal: causas e alterações no sistema estomatognático. Rev Bras Otorrinolaringol. 2000; 66(4):373-9.

11. Marchesan IQ. The speech pathology treatment with alterations of the stomatognathic system. Int $\mathrm{J}$ Orofac Myol. 2000; 26:5-12.

12. Pinho SMR. Avaliação e tratamento da voz. In: Pinho SMR. Fundamentos em Fonoaudiologia.

2. ed. Rio de Janeiro: Guanabara Koogan; 2003. p. 2-40.
13. Filus JF. Estudo de problemas posturais e de aprendizagem em alunos respiradores orais [dissertação]. Maringá (PR): Universidade Estadual de Maringá; 2006.

14. Krakauer LH. Alterações de funções orais nos diversos tipos faciais. In: Marchesan IQ. Tópicos em fonoaudiologia. São Paulo: Lovise; 1995. p.147-54. 15. Santos CAL, Oliveira FAF, Duarte MS, Cunha FL, Almeida RC. Pacientes portadores de obstrução respiratória: avaliação da alteração da altura facial inferior. Rev Gaúcha de Odontol. 2005; 53(1):51-3. 16. Lessa FCR, Enoki C, Feres MFN, Valera FCP, Lima WTA, Matsumoto MAN. Influência do padrão respiratório na morfologia craniofacial. Rev Bras Otorrinolaringol. 2005; 71(2):156-60.

17. Bonatto MTRL, Silva MAA, Costa HO. A relação entre respiração e sistema sensório-motor oral em crianças disfônicas. Rev. CEFAC. 2004; 6(1):58-66. 18. Ferreira ML. A incidência de respiradores bucais em indivíduos com oclusão classe II. J Bras Ortodon Ortop Facial. 1999; 4(21):223-40.

19. Rodrigues MB, Barros RL, Luna TF, Justino HS. Avaliação quantitativa da função tubária e síndrome do respirador oral: estudo de caso. J Bras Fonoaudiol. 2003; 17(4):269-71.

20. Godoy MAB. Problemas de aprendizagem e de atenção em alunos com obstrução das vias aéreas superiores [dissertação]. Maringá (PR): Universidade Estadual de Maringá; 2003.

21. Oliveira AC, Anjos CAL, Silva EHAA, Menezes PL. Aspectos indicativos de envelhecimento facial precoce em respiradores orais adultos. Pró-Fono. 2007; 19(3):305-12.

22. Bicalho GP, Motta AR, Vicente LCC. Avaliação da deglutição em crianças respiradoras orais. Rev. CEFAC. 2006; 8(1):50-5.

23. Moreira DS. Hábitos viciosos nocivos à oclusão. [monografia]. São Paulo (SP): CEFAC - PósGraduação em Saúde e Educação; 1999. $36 f$.

24. Carvalho GD. S.O.S. Respirador bucal: uma visão funcional e clínica da amamentação. São Paulo: Lovise; 2003. 
25. FrassonDJM, MagnaniMBBA, NouerDF, Siqueira $\mathrm{CV}$, Lunardi N. Estudo cefalométrico comparativo entre respiradores nasais e predominantemente bucais. Rev Bras Otorrinolaringol. 2006; 72(1):72-82. 26. Coelho MF, Terra VHTC. Implicações clínicas em pacientes respiradores bucais. Rev Bras Patol Oral. 2004; 3(1):17-9.

27. Calvet CO, Pereira AFV. Alterações periodontais em respiradores bucais. Rev Fac Odontol. 2002; 41(2):21-4.

28. Menezes VA, Leal RB, Pessoa RS, Pontes RMES. Prevalência e fatores associados à respiração oral em escolares participantes do projeto Santo Amaro-Recife, 2005. Rev Bras Otorrinolaringol. 2006; 72(3):394-9.

29. Costa JR, Pereira SRA, Mittri G, Motta JC, Pignatari SS, Weckx LLM. Relação da oclusão dentária com a postura de cabeça e coluna cervical em crianças respiradoras orais. Rev Paul Pediatr. 2005; 23(2):88-93.
30. Andrade FV, Andrade DV, Araujo AS, Ribeiro ACC, Deccax LDG, Nemr K. Alterações estruturais de órgãos fonoarticulatórios e más oclusões dentárias em respiradores orais de 6 a 10 anos. Rev. CEFAC. 2005; 7(3):318-25.

31. Perilo TVC, Motta AR, Las Casas EB, Saffar JME, Costa CG. Avaliação objetiva das forças axiais produzidas pela língua de crianças respiradoras orais. Rev Soc Bras Fonoaudiol. 2007; 12(3):184-90. 32. Cunha DA, Silva GAP, Motta MEFA, Lima $\mathrm{CR}$, Silva HJ. A respiração oral em crianças e suas repercussões no estado nutricional. Rev. CEFAC. 2007; 9(1):47-54. http://dx.doi.org/10.1590/ S1516-18462007000100007

33. Vera CFD, Conde GES, Wajnsztejn R, Nemr K. Transtornos de aprendizagem e presença de respiração oral em indivíduos com diagnóstico de transtornos de déficit de atenção/hiperatividade (TDHA). Rev. CEFAC. 2006; 8(4):441-55. http:// dx.doi.org/10.1590/S1516-18462006000400005

RECEBIDO EM: 13/03/2009

ACEITO EM: 02/11/2009

Endereço para correspondência:

Cintia Megumi Nishimura.

Rua Aristides Lobo, 420 ap. 501

Maringá - PR

CEP:87030-240

E-mail: cnishimura@bol.com.br 